\title{
Papers
}

\section{Achieving the millennium development goals for health Cost effectiveness analysis of strategies to combat malaria in developing countries}

Chantal M Morel, Jeremy A Lauer, David B Evans

This article is part of a series examining the cost effectiveness of strategies to achieve the millennium development goals for health

\begin{abstract}
Objective To determine the cost effectiveness of selected malaria control interventions in the context of reaching the millennium development goals for malaria.

Design Generalised cost effectiveness analysis.

Data sources Efficacy data came from the literature and authors' calculations supported by expert opinion. Quantities for resource inputs came from the literature and from expert opinion; prices came from the WHO-CHOICE database.

Methods Costs were assessed in year 2000 international dollars, and effects were assessed as disability adjusted life years averted by a 10 year implementation programme. Analysis was restricted to sub-Saharan regions where the most deadly form of malaria, Plasmodium falciparum, is most prevalent. The impact on population health for various interventions, and their combinations, was evaluated at selected coverage levels by using a state-transition model. Sensitivity analysis was done for age weights and discounting.

Results High coverage with artemisinin based combination treatments was found to be the most cost effective strategy for control of malaria in most countries in sub-Saharan Africa.

Conclusions A much larger infusion of resources than those currently available is needed to make headway in the fight to roll back malaria. On cost effectiveness grounds, in most areas in sub-Saharan Africa greater coverage with highly effective combination treatments should be the cornerstone of malaria control. However, treatment alone can achieve less than half the total benefit obtainable through a combination of interventions-scaling up the use of impregnated mosquito nets or indoor spraying with insecticides is also critical. Intermittent presumptive treatment of pregnant women can bring a small but important additional health gain at relatively low cost.
\end{abstract}

\section{Introduction}

Each year, more than one million people, mostly children and pregnant women, die from malaria. The human toll is tragic, and the economic cost is enormous. ${ }^{12}$ Most of these deaths could be avoided, however, as effective and affordable ways to prevent and treat malaria exist. In recognition of the scope of the problem, malaria control is embedded in one of the millennium development goals of the United Nations: to "combat HIV/AIDS, malaria and other diseases." ${ }^{3}$

Although insufficient data are available to fully assess global experience since 2000, malaria related mortality seems to have increased since 1990, probably owing to a combination of factors, including increasing exposure to the disease, ${ }^{4}$ increasing resistance to antimalarial drugs, ${ }^{5}$ and stagnant levels of coverage with interventions (R W Snow, personal communication, 2005). Complex emergencies and resistance to insecticides have also contributed. ${ }^{6}$ Achieving the millennium development goals clearly requires a massive scaling up of interventions against malaria.

However, it is important to ask whether current interventions are used appropriately and what is the most cost effective way to scale up activities to the levels needed. In particular, which prevention or treatment strategies, and what combination, are most effective and where? We use a generalised cost effectiveness analysis to examine the costs and effects of scaling up seven interventions against malaria and their most promising combinations. This paper deviates from others in this series ${ }^{7}$ by focusing only on sub-Saharan Africa, where $90 \%$ of deaths from malaria occur. ${ }^{8}$

Whereas most economic studies have compared the relative cost effectiveness of implementing interventions for prevention or treatment individually-that is, considering the best use of small amounts of additional resources-this study used a generalised framework allowing for interactions, as well as for consideration of whether current practice is optimal and what the implications are of massively scaling up.

\section{Methods}

\section{Geographical focus}

We focused on two sub-Saharan African regions: Afr-E (predominantly Southern and Eastern Africa), defined as African countries with high child mortality (all causes) and very high adult mortality (all causes), and Afr-D (predominantly Western Africa), African countries with high child mortality and high adult mortality. Table A on bmj.com gives a list of the countries by region.

Both regions are predominantly areas with endemic high transmission of malaria due to Plasmodium falciparum, although the burden of disease differs somewhat. According to the World Health Report 2000, incidence of symptomatic malaria in children aged under 5 years was 1436 per thousand in Afr-D, whereas in Afr-E it was 1184 per thousand; these differences are

Extra tables and figures and an appendix are on bmj.com 
due to patterns of urbanisation and the elevation of populated sites. In Afr-E, cause specific child mortality is slightly higher at 8 per thousand as opposed to 7 per thousand in Afr-D.

\section{Interventions}

A limited number of means are available to fight malaria. Preventive interventions, based on vector control, include insecticide treated bed nets and indoor residual spraying. For treatment of malaria, several drugs exist and a few are relatively inexpensive. However, resistance to most drugs is growing rapidly. Recently, combination treatments with and without artemisinin derivatives have been tested and found not only to be effective but also to slow the growth of resistance. ${ }^{9}$ Intermittent treatment of pregnant women-aimed largely at reducing neonatal mortality-is also an option. We evaluated seven individual interventions and combinations thereof (box 1).

Some countries in sub-Saharan Africa still officially recommend chloroquine as first line treatment for malaria despite increasing resistance and declining cure rates. Although others have moved to sulfadoxine-pyrimethamine, resistance has also compromised its effectiveness. As a result, awareness is growing of the need to increase the use of artemisinin derivatives (especially in combination treatment), as resistance to these compounds is still extremely low (even non-existent) in sub-Saharan Africa. ${ }^{10}$ In this study, we evaluated the cost effectiveness of chloroquine, sulfadoxine-pyrimethamine, nonartemisinin based combinations, and artemisinin based combinations as first line treatment (we did not consider complicated malaria needing admission to hospital).

\section{Population at risk and coverage}

We evaluated interventions at 50\%, 80\%, and 95\% target coverage to allow for unit costs and effectiveness that may vary with coverage. We estimated effective coverage as target coverage multiplied by population at risk. ${ }^{8}$ We based region-wide estimates of population at risk (the proportion living in a malaria

Box 1: Interventions evaluated

- Insecticide treated bed nets (ITN)

- Indoor residual spraying (IRS)

- Case management with chloroquine (CQ)

- Case management with sulfadoxine-pyrimethamine (SP)

- Case management with non-artemisinin based (CQ-SP)

combination treatment (Comb)

- Case management with artemisinin based combination treatment (ACT)

- Intermittent presumptive treatment with $\mathrm{SP}$ in pregnancy (IPTp)

(See appendix on bmj.com for details)

Table 1 Current coverage* with selected malaria control interventions

\begin{tabular}{lcc} 
Intervention & Afr-D (\%) & Afr-E (\%) \\
\hline Case management with chloroquine & 23 & 27 \\
\hline Case management with sulfadoxine-pyrimethamine (SP) & 3 & 3 \\
\hline $\begin{array}{l}\text { Case management with non-artemisinin based combination } \\
\text { treatment }\end{array}$ & 0 & 0 \\
$\begin{array}{l}\text { Case management with artemisinin based combination } \\
\text { treatment }\end{array}$ & 0 & 0 \\
$\begin{array}{l}\text { Insecticide treated bed nets } \\
\text { Indoor residual spraying }\end{array}$ & 2 & 2 \\
\hline Intermittent presumptive treatment with SP in pregnancy & 0 & 3 \\
\hline
\end{tabular}

*Percentage of people at risk who are given the drug at outpatient clinic or antenatal clinic, sleep under an insecticide treated net, or live in a house that has been sprayed.

endemic area: 98\% for Afr-D and 69\% for Afr-E) on country specific figures published in 2003. ${ }^{8}$ Table 1 shows estimates of current coverage, ${ }^{8}$ used for calculating the null scenario. ${ }^{7}$

\section{Estimating the net effectiveness of interventions}

We expressed the efficacy of bed nets and indoor spraying as a reduction in incidence and, thereby, a reduction in mortality, modelled here through case fatality (table 2 ). We estimated the net effectiveness of treatment, taking into account patients' behaviour (adherence to the regimen), pharmacokinetics (probability of success when the regimen is not followed), and biogenetics (resistance of the parasite to the drug). These factors (table 3) determine the number of expected treatment failures, ${ }^{11}$ which we subtracted from a common baseline of $98 \%$ efficacy. We reduced the net effectiveness of bed nets, but not spraying, to account for imperfect adherence. Table 4 shows estimates of net effectiveness. Table B on bmj.com reports the detailed assumptions on effectiveness.

A population model ${ }^{12}$ combined estimates of incidence, prevalence, and mortality (table 5$)^{13}$ with estimates of prevalence and severity from the burden of disease study to project the population impact of intervention scenarios in terms of healthy

Table 2 Baseline efficacy (both Afr-D and Afr-E)

\begin{tabular}{|c|c|c|}
\hline Intervention & $\begin{array}{c}\text { Baseline } \\
\text { reduction in } \\
\text { incidence }(\%)\end{array}$ & $\begin{array}{c}\text { Baseline } \\
\text { reduction in case } \\
\text { fatality* }(\%)\end{array}$ \\
\hline Insecticide treated bed nets & 50 & 20 \\
\hline Indoor residual spraying & 50 & 20 \\
\hline Case management with chloroquine & 0 & 98 \\
\hline $\begin{array}{l}\text { Case management with sulfadoxine-pyrimethamine } \\
\text { (SP) }\end{array}$ & 0 & 98 \\
\hline $\begin{array}{l}\text { Case management with non-artemisinin based } \\
\text { combination treatment }\end{array}$ & 0 & 98 \\
\hline $\begin{array}{l}\text { Case management with artemisinin based combination } \\
\text { treatment }\end{array}$ & 0 & 98 \\
\hline $\begin{array}{l}\text { Intermittent presumptive treatment with SP in } \\
\text { pregnancy }\end{array}$ & 0 & 5 \\
\hline
\end{tabular}

Table 3 Parameters used for the calculation of net effectiveness

\begin{tabular}{|c|c|c|c|c|}
\hline \multirow[b]{2}{*}{ Intervention } & \multicolumn{2}{|c|}{ Resistance } & \multicolumn{2}{|c|}{ Behavioural/drug characteristics } \\
\hline & $\boldsymbol{R}_{0}$ & $r$ & Adherence (\%) & $\begin{array}{l}\text { Probability of success when not } \\
\text { fully compliant (\%) }\end{array}$ \\
\hline Insecticide treated bed nets & - & - & 65 & 0 \\
\hline Indoor residual spraying & - & - & 100 & 0 \\
\hline Case management with chloroquine & 0.3 & 0.1 & 40 & 20 \\
\hline Case management with sulfadoxine-pyrimethamine (SP) & 0.1 & 0.4 & 90 & 0 \\
\hline Case management with non-artemisinin based combination treatment & 0.1 & 0.1 & $35^{\star}$ & 45 \\
\hline Case management with artemisinin based combination treatment & 0.001 & 0.05 & $40 \dagger$ & 45 \\
\hline Intermittent presumptive treatment with SP in pregnancy & 0.1 & 0.1 & 80 & 10 \\
\hline
\end{tabular}

${ }^{*}$ Chloroquine-SP assumed to be coadministered.

†Combination assumed to be blister packed, co-formulated, or both. 
Table 4 Net effectiveness of the interventions

\begin{tabular}{lcc} 
Intervention & $\begin{array}{c}\text { Reduction in } \\
\text { incidence (\%) }\end{array}$ & $\begin{array}{c}\text { Reduction in case } \\
\text { fatality (\%) }\end{array}$ \\
\hline Insecticide treated bed nets & 50 & 20 \\
\hline Indoor residual spraying & 50 & 20 \\
\hline Case management with chloroquine & - & 27 \\
\hline $\begin{array}{l}\text { Case management with sulfadoxine-pyrimethamine } \\
(\text { SP) }\end{array}$ & - & 44 \\
$\begin{array}{l}\text { Case management with non-artemisinin based } \\
\text { combination treatment }\end{array}$ & - & 48 \\
$\begin{array}{l}\text { Case management with artemisinin based } \\
\text { combination treatment }\end{array}$ & - & 63 \\
$\begin{array}{l}\text { Intermittent presumptive treatment with SP in } \\
\text { pregnancy }\end{array}$ & - & 3.4 \\
\hline
\end{tabular}

years of life lived. ${ }^{7}$ Differences in total population healthy years under the intervention and baseline scenarios are expressed as disability adjusted life years (DALYs) averted.

\section{Costs}

Estimated costs measure the value of resources needed to provide the intervention ${ }^{7}$ and are expressed in international dollars (\$int, a hypothetical unit of currency that has the same purchasing power that the US\$ has in the United States at a given point in time, thus showing the average value of local currency units within each region's borders). We calculated costs in the light of experience from effectiveness trials, using data from the WHO-CHOICE database, existing literature, and expert opinion. ${ }^{7}$ As we explicitly assumed training of human resources to be a substantial part of malaria interventions, training costs are reported separately. We used the CostIt model (WHO, 2002) to aggregate cost components and total costs for the 10 year implementation horizon. Details of the approach are discussed by Baltussen et al. ${ }^{14}$

Table 5 World Health Organization estimates of the burden of malaria

\begin{tabular}{lccc} 
& Incidence & Deaths & DALYs \\
\hline Afr-D & 176547940 & 515528 & 19088877 \\
\hline Afr-E & 163442874 & 470845 & 17680061 \\
\hline Worldwide & 381987866 & 1120697 & 41998576 \\
\hline
\end{tabular}

DALY=disability adjusted life year.

Source: WHO programme on global burden of disease.
Unit costs-We obtained unit costs of inputs, such as salaries, capital equipment, drugs, storage, buildings, office supplies, and furniture from a review of the literature supplemented by primary data from several countries (a full list of estimated unit costs is available at www.who.int/evidence/cea). Additional details can be found in Johns et al, Johns and Baltussen, and Adam et al. ${ }^{15-17}$

Distribution costs-We assumed distribution costs to be most sensitive to changes in coverage levels and calculated them with a standard mark-up based on the average of free on board; cost, insurance, and freight; and additional trade related distributional costs. ${ }^{15} 16$

Media costs-A substantial component of malaria control is creating public awareness of and demand for health services. We accordingly included media costs for all interventions and estimated them according to whether they consisted of a centrally determined policy change (for example, case management guidelines) or were intended to change population behaviour (for example, insecticide treated bed nets). We included both public campaigns (all interventions) and targeted social marketing (bed nets only, through an extensive level of outreach). We obtained benchmarks from cost analyses of existing malaria control programmes in sub-Saharan Africa. ${ }^{18}$

Labour costs-We estimated labour costs according to the educational level of the worker-for example, administrative staff or medical staff-and the number of full time equivalents needed for administration, training, or delivery of the intervention.

Cost profiles- Figures 1 and 2 summarise cost profiles for $95 \%$ coverage (generally the most efficient coverage level) by patient, programme, and training costs. Note that for some interventions patient costs are the smallest proportion of total costs.

\section{Results}

Population level cost effectiveness estimates for individual and combined interventions are shown in table 6 (dominant interventions only) and in figures 3 and 4 (all interventions; figures $\mathrm{A}$ and $\mathrm{B}$ on bmj.com give more detail). Complete results are reported in table $\mathrm{C}$ on bmj.com.

The "expansion paths" in figures 3 and 4, described in the methods paper for this series, ${ }^{7}$ show the order in which interven-

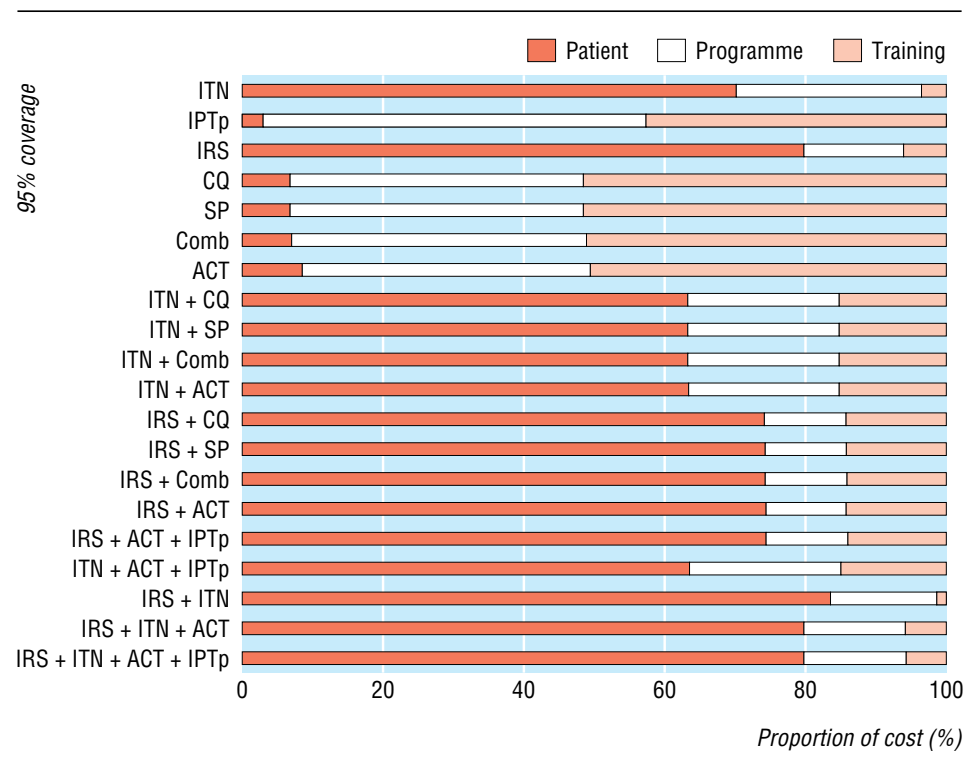

Fig 1 Cost profile of interventions at 95\% coverage, Afr-D. See box 1 for abbreviations 
tions would be selected at different levels of resource availability. Notable differences exist between the regions. In Afr-D, case management with artemisinin based combination treatments at $80 \%$ target coverage is the most cost effective intervention overall and would be the first choice where resources are limited, whereas a target coverage of $95 \%$ is needed in Afr-E. In Afr-D, the second intervention on the path represents an increase in coverage with artemisinin based combination treatment. In both regions, however, use of insecticide treated bed nets $(95 \%$ coverage) would be added after coverage with artemisinin based combination treatment reaches 95\%, although in Afr-D intermittent presumptive treatment with sulfadoxine-pyrimethamine in pregnancy (95\% coverage) would be added at the same stage. In both regions, the ultimate stage involves the use of case management with artemisinin based combination treatment, insecticide treated nets as well as indoor residual spraying, and intermittent presumptive treatment in pregnancy, all at 95\% coverage.

All malaria interventions are highly cost effective, with average cost effectiveness ratios (except intermittent presumptive treatment with sulfadoxine-pyrimethamine in pregnancy) in the order of 10-100 \$int/DALY averted. Nevertheless, the size of potential health gains, as well as incremental cost effectiveness ratios, are more favourable in Afr-D than in Afr-E, as a higher proportion of the population is at risk in Afr-D. That allows more people to be covered, thereby reducing the costs per person covered (fig 5 , fig 6 , table 6 ).

\section{Discussion}

\section{Principal findings}

Progress towards the millennium development goals has been disappointing and major action is needed if sub-Saharan Africa is to achieve the malaria specific target. Although external assistance is critical, countries also need to re-evaluate current strategies (box 2). A distinguishing characteristic of this analysis is the health system focus, integrating evidence about costs and effectiveness at a level relevant for policy makers.

Recent developments such as the Global Fund to Fight AIDS, Tuberculosis and Malaria, and the interest of various foundations, promise increased funding for malaria control. To date, however, attention has been focused on the drugs, other expendables, and, to a limited degree, additional staffing needed to scale up health interventions. This narrow focus ignores the additional system resources needed to implement and sustain a massive scale up of activity, as well as the relatively fixed constraints on existing staff time and health facilities. Our results suggest that the costs of reaching agreed targets are considerably greater than the costs that receive most current attention.

Artemisinin based combination treatments are more expensive than other drugs, and, in the short term, non-artemisinin based combinations such as amodiaquine-sulfadoxinepyrimethamine might be used as an interim measure. ${ }^{19}$ However, as resistance to these drugs is increasing, recommendations should be guided by local resistance patterns, ${ }^{20}$ and a full switch to artemisinin based combinations should be seriously considered in all areas with high transmission of drug resistant $P$ falciparum malaria.

\section{Differences from other studies}

This analysis differs from previous studies for malaria in that we have specifically assessed combinations of interventions, rather than assuming that costs and effects sum up when interventions are used concurrently. Such studies can be misleading at worst, and, at best, decision makers lack necessary information about relevant combinations.

In the only previous study analysing sub-Saharan Africa, Goodman et al found the cost/DALY averted of insecticide treated bed nets to be $\$ 19-85$ (US $\$, 1995$ ) compared with $\$ 16$-29 for indoor residual spraying. ${ }^{21}$ The estimates presented here ( 30 \$int /DALY for either intervention at 95\% coverage in Afr-D and $\sim 40 \$$ int/DALY at 95\% coverage in Afr-E) are roughly comparable. However, what does not emerge from typical cost effectiveness trials is the conclusion that implementing spraying and nets together has a cost effectiveness ratio roughly similar to that of either one alone ( 35 \$int/DALY at 95\% coverage in Afr-D and $\sim 48 \$$ int/DALY at $95 \%$ coverage in Afr-E), from the realisation of substantial efficiencies due to shared costs (reducing the unit costs of both) counterbalanced by the reduced health benefits resulting from adding spraying to widespread use of bed nets.

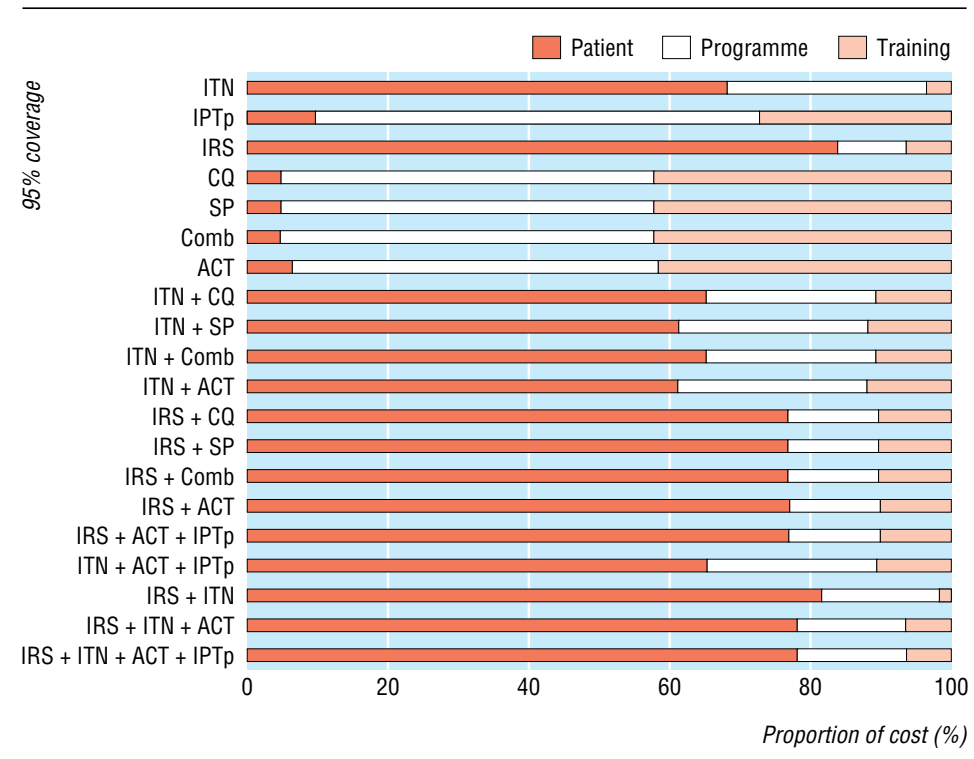

Fig 2 Cost profile of interventions at 95\% coverage, Afr-E. See box 1 for abbreviations 
Table 6 Costs, effectiveness, and cost effectiveness of the health maximising set of interventions (see table $\mathrm{C}$ on bmj.com for detailed results for all interventions)

\begin{tabular}{|c|c|c|c|c|}
\hline Region and intervention & $\begin{array}{c}\text { Average } \\
\text { yearly } \\
\text { costs (\$int) }\end{array}$ & $\begin{array}{l}\text { Average yearly } \\
\text { effectiveness } \\
\text { (DALYs } \\
\text { averted) }\end{array}$ & $\begin{array}{c}\text { Average } \\
\text { cost } \\
\text { effectiveness } \\
\text { (\$int/DALY } \\
\text { averted) }\end{array}$ & $\begin{array}{l}\text { Incremental } \\
\text { cost } \\
\text { effectiveness } \\
\text { (\$int/DALY } \\
\text { averted) } \\
\end{array}$ \\
\hline \multicolumn{5}{|l|}{ Afr-D } \\
\hline $\begin{array}{l}\text { Case management with } \\
\text { artemisinin based } \\
\text { combination therapy ( } 80 \% \\
\text { coverage) }\end{array}$ & 72386626 & 7771018 & 9 & 9 \\
\hline $\begin{array}{l}\text { Case management with } \\
\text { artemisinin based } \\
\text { combination therapy (95\% } \\
\text { coverage) }\end{array}$ & 95609717 & 9254473 & 10 & 10 \\
\hline $\begin{array}{l}\text { Insecticide treated bed nets } \\
\text { plus case management with } \\
\text { artemisinin based } \\
\text { combination therapy plus } \\
\text { intermittent presumptive } \\
\text { treatment in pregnancy } \\
\text { (95\% coverage) }\end{array}$ & $\begin{array}{c}315546 \\
119\end{array}$ & 12972791 & 24 & 59 \\
\hline $\begin{array}{l}\text { Indoor residual spraying plus } \\
\text { insecticide treated bed nets } \\
\text { plus case management with } \\
\text { artemisinin based } \\
\text { combination therapy plus } \\
\text { intermittent presumptive } \\
\text { treatment in pregnancy } \\
\text { (95\% coverage) }\end{array}$ & $\begin{array}{c}467673 \\
321\end{array}$ & 14561792 & 32 & 96 \\
\hline \multicolumn{5}{|l|}{ Afr-E } \\
\hline $\begin{array}{l}\text { Case management with } \\
\text { artemisinin based } \\
\text { combination therapy (95\% } \\
\text { coverage) }\end{array}$ & 73000256 & 5886159 & 12 & 12 \\
\hline $\begin{array}{l}\text { Insecticide treated bed nets } \\
\text { plus case management with } \\
\text { artemisinin based } \\
\text { combination therapy ( } 95 \% \\
\text { coverage) }\end{array}$ & $\begin{array}{c}254755 \\
715\end{array}$ & 9138452 & 28 & 56 \\
\hline $\begin{array}{l}\text { Indoor residual spraying plus } \\
\text { insecticide treated bed nets } \\
\text { plus case management with } \\
\text { artemisinin based } \\
\text { combination therapy ( } 95 \% \\
\text { coverage) }\end{array}$ & $\begin{array}{c}441216 \\
954\end{array}$ & 10721678 & 41 & 118 \\
\hline $\begin{array}{l}\text { Indoor residual spraying plus } \\
\text { insecticide treated bed nets } \\
\text { plus case management with } \\
\text { artemisinin based } \\
\text { combination therapy plus } \\
\text { intermittent presumptive } \\
\text { treatment in pregnancy } \\
\text { (95\% coverage) }\end{array}$ & $\begin{array}{c}442342 \\
075\end{array}$ & 10729154 & 41 & 151 \\
\hline
\end{tabular}

DALY=disability adjusted life year; \$int=international dollar.

\section{Limitations of the analysis}

The relative effectiveness of spraying and nets has been debated..$^{22}{ }^{23}$ Although we have assumed that they are equally effective in reducing morbidity and mortality, their respective advantages in a given setting will depend on whether mosquitoes are endophilic, the length of time they rest indoors, ${ }^{24}$ and the time children go to bed.

People's willingness to use bed nets effectively is often reduced by user charges and the need to reimpregnate nets if they are not long lasting. Moreover, nets must be kept in good condition and used consistently despite their at times uncomfortable insulating properties. ${ }^{25}$

Indoor residual spraying, on the other hand, is generally paid for and carried out by public authorities once or twice a year, which in theory makes adherence less burdensome; however, house owners may replaster or paint over recently sprayed walls because of the smell of insecticide or visible deposits, ${ }^{23}$ and resi-

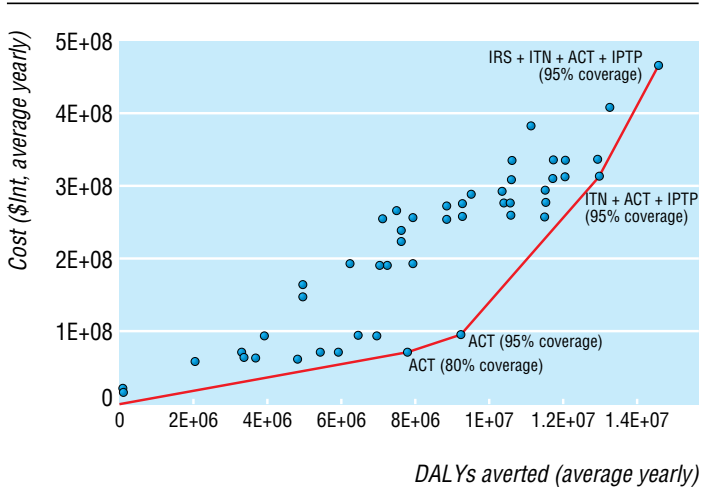

Fig 3 Cost effectiveness plane showing 60 analysed interventions (20 individual and combination interventions at three assumed coverage levels) and expansion path (see text), Afr-D. DALY=disability adjusted life year; see box 1 for other abbreviations

dents must be willing to let sprayers into their homes. Furthermore, the relative effectiveness of these interventions will depend on local transmission patterns. For example, in epidemic-prone areas, spraying is likely to be an effective emergency measure as it can be implemented relatively quickly and needs less logistic effort than a bed net campaign. ${ }^{25}$

Our assumptions about the effectiveness of intermittent presumptive treatment with sulfadoxine-pyrimethamine in pregnancy were very conservative. We did not include health benefits for the mother, and the effect on the infant was limited to a reduction in case fatality due to malaria in the first year of life.

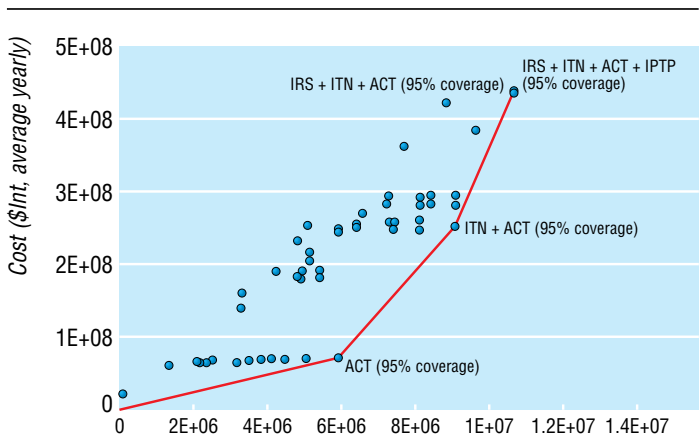

$D A L Y$ s averted (average yearly)

Fig 4 Cost effectiveness plane showing 60 interventions (20 individual and combination interventions at three assumed coverage levels) and expansion path (see text), Afr-E. DALY=disability adjusted life year; see box 1 for other abbreviations

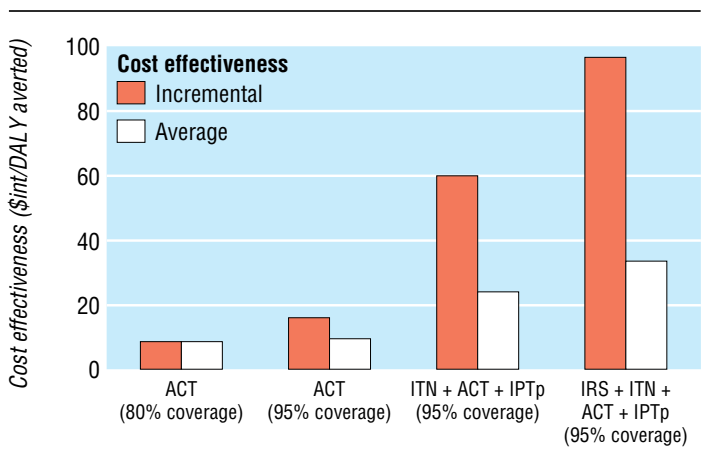

Fig 5 Incremental and average cost effectiveness ratios for the health maximising interventions, Afr-D. DALY=disability adjusted life year; see box 1 for other abbreviations 


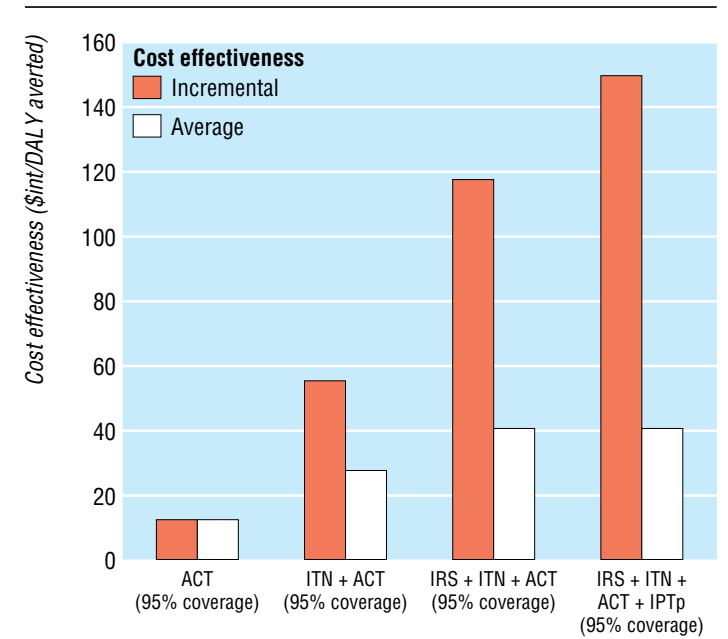

Fig 6 Incremental and average cost effectiveness ratios for the health maximising interventions, Afr-E. DALY=disability adjusted life year; see box 1 for other abbreviations

Costing of intermittent presumptive treatment was as part of a routine antenatal package of care with only the incremental costs of dedicated activities considered.

Owing to lack of data on reductions in all cause mortality, we assumed that when drugs are taken under ideal conditions they are $98 \%$ effective in preventing cause specific mortality. Although we did try to account for parasite resistance, imperfect adherence to treatment, and pharmacokinetic properties, actual effectiveness is likely to include factors omitted in the analysis. Modelling implementation over a 10 year period, moreover, may not fully capture the contrast between drugs with high versus low growth rates of resistance (for example, sulfadoxinepyrimethamine $v$ artemisinin based combination treatment). Consequently, our estimate of the cost effectiveness of artemisinin based combination treatments may be conservative compared with when a longer term perspective is taken.$^{26}$ Finally, the study allows no conclusions to be drawn about financing methods, which can be of utmost importance. ${ }^{27}$

\section{Implications of the study}

In conclusion, with the availability of increased international funding, a re-evaluation of existing and potential strategies is appropriate. An adequate portion of new funds should be allocated to strengthening the health system components of

\footnotetext{
Box 2: Main messages-malaria and the millennium development goals

- Five years on from the declaration of the millennium development goals, progress in controlling malaria remains uncertain, particularly in sub-Saharan Africa

- Health system decision makers in most countries in sub-Saharan Africa (see text for details) should consider switching treatment strategies to artemisinin based combinations as the foundation of effective malaria control

- Reinvigorating efforts to scale up use of impregnated mosquito nets and indoor spraying with insecticides is critical

- Where these interventions are being successfully implemented, intermittent presumptive treatment of pregnant women can bring a small but important additional health gain

- A much larger infusion of resources than those currently available is needed to make headway in the fight to roll back malaria
}

\section{What is already known on this topic}

Insufficient data are available to fully assess global malaria trends since 2000 , but malaria related mortality seems to have increased since 1990

Despite the existence of effective preventive and curative strategies, current malaria control in sub-Saharan Africa remains poor

Achieving the malaria specific millennium development goal requires a massive scaling up of interventions in sub-Saharan Africa

\section{What this study adds}

This study quantifies the advantages of shifting resources towards artemisinin based combination treatment, as well as of using preventive and curative interventions in combination

A much larger infusion of resources than those currently available, and more attention to health system strengthening, is needed to make headway in the fight to roll back malaria

malaria interventions, which will determine the long term viability of these activities.

On purely cost effectiveness grounds, this study suggests that most countries in sub-Saharan Africa should be moving to combination therapy with new drugs as rapidly as possible and that efforts should be regenerated to ensure that interventions based on prevention, such as nets and spraying, are scaled up appropriately. Even where the health system is weak, prevention will never be a stand alone strategy, as informal distribution mechanisms ensure the availability of antimalarials-both effective and highly ineffective-even in the most isolated areas. All attempts should be made to ensure that the antimalarials that are accessed are indeed those that work. These are relatively simple messages, but ones that remain robust even when underlying assumptions are varied significantly.

We thank Anne Mills, Jo Lines, Chris Curtis, Brian Greenwood, and Tessa Tan-Torres for their assistance over the course of this project. We also thank Eline Korenromp, Kamini Mendis, Pascal Ringwald, Andrea Bosman, Wilson Were, and Peter Olumese for their helpful comments.

Contributors: CMM and JAL contributed equally to the planning, conduct, interpretation, and writing up of the work. CMM was responsible for assessing and estimating all malaria specific data and methods; JAL was responsible for the final estimation and modelling of costs and effects at population level. DBE revised the analysis plan and contributed critical interpretive content. All authors revised and approved the final draft.JAL is the guarantor.

Funding: CMM received consulting fees from the World Health Organization.The views expressed are solely those of the authors and do not necessarily reflect the decisions or stated policy of the London School of Hygiene and Tropical Medicine or the World Health Organization.

Competing interests: None declared.

Sachs J, Malaney P. The economic and social burden of malaria. Nature 2002;415:680-5 Chima RI, Goodman CA, Mills A. The economic impact of malaria in Africa: a critica review of the evidence. Health Policy 2003;63:17-36.

United Nations. Millennium development goals report New York: United Nations, 2005.

Hay SI, Guerra CA, Tatem AJ, Noor AM, Snow RW. The global distribution and population at risk of malaria: past, present, and future. Lancet Infect Dis 2004;4:327-36.

White NJ. The assessment of antimalarial drug efficacy. Trends Parasitol 2002:18:458-64

6 Roll Back Malaria, World Health Organization, UNICEF. World malaria report 2005. Geneva: WHO, 2005.

7 Evans DB, Adam T, Tan-Torres Edejer T, Lim SS, Cassels A, Evans TG, et al. Achieving the millennium development goals for health: Time to reassess strategies for improving health in developing countries? BMJ 2005;331:1133-6. 
8 World Health Organization, UNICEF. The Africa malaria report 2003. Geneva: WHO, UNICEF, 2003:120.

9 White N. Delaving antimalarial drug resistance with combination chemotherapy. Parassitologia 1999;41:301-8

10 White NJ. Averting a malaria disaster. Lancet 1999;353:1965-7.

11 Goodman C, Coleman PG, Mills AJ. Changing the first line drug for malaria treatment-cost-effectiveness analysis with highly uncertain inter-temporal trade-offs. Health Econ 2001;10:731-49.

12 Lauer JA, Roehrich K, Wirth H, Charette C, Gribble S, Murray CJL. PopMod: a longitudinal population model with two interacting disease states. Cost Eff Resour Alloc 2003; 1:6.

13 World Health Organization. Global burden of disease estimates 2002. www3.who.int whosis/menu.cfm?path = evidence,burden (accessed 16 Sept 2004).

14 Baltussen R, Adam T, Tan-Torres Edejer T. Methods for generalised cost-effectiveness analyBaltussen R, Adam T, Tan-Torres Edejer T. Methods for generalised cost-effectiv
sis: a guide. WHO guidelines on cost-effectiveness analysis. Geneva: WHO, 2003.

15 Johns B, Baltussen R, Adam T, Hutubessy R. Programme costs in the economic evaluation of health interventions. Cost Eff Resour Alloc 2003;1:1.

16 Johns B, Baltussen R. Accounting for the costs of scaling up health interventions. Health Econ 2004;13:1117-24.

17 Adam T, Evans D, Murray C. Econometric estimation of country-specific hospital costs Cost Eff Resour Alloc 2003;1:3.

18 Stevens W, Wiseman V, Ortiz J, Chavasse D. Cost-effectiveness of a nationwide insecticide treated net programme: the case of Malawi. Malar J 2005;4:22.

19 Staedke SG, Mpimbaza A, Kamya MR, Nzarubara B, Dorsey G, Rosenthal PJ. Combination treatments for uncomplicated falciparum malaria in Kampala, Uganda: tion treatments for uncomplicated falciparum

20 Bakyaita N, Dorsey G, Yeka A, Banek K, Staedke SG, Kamya MR, et al Sulfadoxine-pyrimethamine plus chloroquine or amodiaquine for uncomplicated falciparum malaria: a randomised, multisite trial to guide national policy in Uganda. Am J Trop Med Hyg 2005;72:573-80

21 Goodman CA, Coleman PG, Mills AJ. Cost-effectiveness of malaria control in sub-Saharan Africa. Lancet 1999;354:378-84.
22 Guyatt HL, Kinnear J, Burini M, Snow RW. A comparative analysis of insecticide-treated nets and indoor residual spraying in highland Kenya. Health Policy Plan 2002;17:14453 .

23 Goodman CA, Minzava AEP, Diamini SS, Sharp BL, Mthembu DJ, Gumede JK. Comparison of the cost and cost-effectiveness of insecticide-treated bednets and residual house-spraying in KwaZulu-Natal, South Africa. Trop Med Int Health 2001;6:280-95.

24 Sharp BL, LeSueur D, Bekker P. Effect of DDT on survival and blood feeding success of Anopheles arabiensis in northern Kwazulu, Republic of South Africa. J Am Mosq Comtrol Assoc 1990;6:197-202.

25 Curtis CF, Mnzava AEP. Comparison of house spraying and insecticide-treated nets for malaria control. Bull World Health Org 2000;78:1389-400.

26 Coleman PG, Morel CM, Shillcutt SD, Goodman CA, Mills AJ. A threshold analysis of the cost-effectiveness of artemisinin-based combination therapies in sub-Saharan the cost-effectiveness of artemisinin-based
Africa. Am J Trop Med Hyg 2004;71:196-204.

27 Hanson K, Goodman C, Lines J, Meek S, Bradley D, Mills A. The economics of malaria control interventions. Geneva: WHO Global Forum for Health Research, 2004

(Accepted 12 October 2005)

doi 10.1136/bmj.38639.702384.AE

Health Policy Unit, Department of Public Health and Policy, London School of Hygiene and Tropical Medicine, London WC1E 7HT

Chantal M Morel research fellow

Costs, Effectiveness, Expenditure and Priority Setting Team, Health Systems Financing Department, World Health Organization, Geneva, Switzerland Jeremy A Lauer economist

Health Systems Financing Department, World Health Organization David B Evans director

Correspondence to: C M Morel Chantal.Morel@lshtm.ac.uk 